\title{
Geloof sonder sekerhede? In gesprek met Anton van Niekerk
}

\author{
Conradie, Ernst \\ University of the Westen Cape \\ econradie@uwc.ac.za
}

\begin{abstract}
Faith without certainties? In conversation with Anton van Niekerk

In this review article of Anton A van Niekerk's recent book Geloof sonder Sekerhede: Hoe kan ek nog glo? (Faith without certainties: How can I still believe?) (2014, Kaapstad: Lux Verbi. ISBN: 9780796318992), three creative tensions in Van Niekerk's book are identified and discussed. The tensions between orthodoxy and orthopraxy, between certainty and doubt and between scientific knowledge and the knowledge of faith. In each case, the question is raised to what extent Van Niekerk's own emphases are context dependent.
\end{abstract}

Die eerste uitgawe van Anton van Niekerk se boek Geloof sonder sekerhede het in 2005 by Lux Verbi verskyn. Die argument van die tweede, hersiene uitgawe van 2014 bly dieselfde, naamlik dat die Christelike geloof (al gaan dit dan met onsekerhede gepaard) implikasies het vir die manier waarop ons lewe, veral in die Suid-Afrikaanse konteks. Dit behels 'n soeke na sin te midde van ervarings van onsekerheid op talle verskillende vlakke, insluitende oor die inhoud van die Christelike geloof.

Die boek bestaan steeds uit twee afdelings. Die eerste afdeling, "Op soek na 'n meer eietydse geloof", is grootliks onveranderd behalwe om enige onduidelikhede te help opklaar. Die tweede afdeling, "Geloof en lewensin in die praktyk" is meer ingrypend verander, ten dele omdat die konteks verander het en gegewe verdere biomediese ontwikkelinge. 'n Nuwe hoofstuk is byvoorbeeld ingevoeg oor die moontlikheid van die "verbetering" van die mens se genetiese samestelling op grond van biotegnologiese ingenieurswese. Daar is ook 'n welkome toevoeging van 
'n hoofstuk oor die huidige uitdagings in die Suid-Afrikaanse konteks, veral gegewe die blywende invloed van apartheid. In hierdie twee afdelings bepleit Van Niekerk, myns insiens tereg, teenoor 'n ongebreidelde utilitarisme, die belang van 'n etiek van verantwoordelikheid ten einde byvoorbeeld bio-etiese vrae (p 217-221) en die moontlikheid van "menslike verbetering" (p 248-250) aan te spreek. Ek vind die wyse waarop só 'n etiek van verantwoordelikheid met die motief van herskepping in verband gebring word interessant (p 247-250, 295) en wonder of Van Niekerk hier aansluiting vind by die wyse waarop die begrip (op heel uiteenlopende wyses) by Bavinck, Noordmans, Van Ruler, Moltmann en Heyns verstaan word (sien Conradie 2013c).

In hierdie bydrae wil ek fokus op veral drie "kreatiewe spanninge" (David Bosch) wat in die boek aanwesig is, naamlik tussen ortodoksie en ortopraksie, tussen sekerheid en onsekerheid en tussen geloofskennis en wetenskaplike kennis. Daar is ander soortgelyke spanninge wat ook genoem kan word sonder om daarby stil te staan, naamlik rondom die vraag of God in die midde of op die grense van die werklikheid te vinde is ( $\mathrm{p} 88$ ), oor God se transendensie en immanensie, oor dood en lewe ( $\mathrm{p}$ 277-301) en oor geheel en dele (p 84-85) (sien hieroor wel Conradie 2006 en 2013a).

\section{Kreatiewe spanninge}

'n Kreatiewe spanning bestaan waar daar wel twee kante van 'n saak bestaan wat algemeen erken word (Bosch 1991:381-389). Dit kan daarom nie sonder meer opgelos word deur 'n kritiek teen bipolêre denke nie, alhoewel die spanning wel dialekties (en dan altyd voorlopig) opgehef kan word. Dit gaan daarom nie hier oor 'n Aristoteliese mediaan nie, maar om die spanning vol te hou ter wille van die vrugbaarheid daarvan. Retories gesproke sal daar altyd sommige wees wat die een kant van die saak beklemtoon juis omdat hulle dink dat ander daardie kant onderbeklemtoon. Dieselfde persoon mag daarom in verskillende omstandighede, afhangende van wie die gespreksgenoot is, verskillende kante van die saak beklemtoon.

Die konteks is hier belangrik op verskeie vlakke. Anton van Niekerk skryf as 'n Stellenbosse filosoof, maar ook as 'n gelegitimeerde bedienaar 
van die Woord van die Ned Geref Kerk. Hy skryf hoofsaaklik vir lidmate van die NG Kerk, in die dampkring van die Universiteit van Stellenbosch (wat ver en wyd strek), wat beïnvloed is deur die intellektuele en politieke uitdagings van moderniteit, maar wat ook ontgogel is met enige aansprake op vaste sekerhede, veral ten opsigte van politieke manifeste of ortodokse leerstellings. Hy skryf hier in Afrikaans, met kenmerkende heldere formulerings en klinkklare logika. Hy verwoord die onderliggende spanninge wat by sy implisiete lesers voorkom en help hulle verder met eerlike ondersoek en toepaslike insigte.

As resensent deel ek heelwat van hierdie konteks, gegewe dat ek op Stellenbosch woon sedert 1967, Afrikaans as huistaal het en dieselfde opleiding in filosofie en teologie aan dieselfde universiteit ontvang het, een dekade later. Ek deel ook 'n verwantskap met die NG Kerk, alhoewel ek tans 'n lidmaat van die Verenigende Gereformeerde Kerk in SuiderAfrika is - wagtend om na my "moeder" terug te keer wanneer strukturele kerkeenheid 'n werklikheid word. Ek is egter sedert 1993 werksaam by die Universiteit van Wes-Kaapland ('n ander wêreld) waar ek sistematiese teologie en ook etiek doseer. Die opleiding is volledige ekumenies en die teologie studente kom uit elke moontlike kerklike tradisie. Die veel groter groep etiek studente kom uit talle ander dissiplines en fakulteite. Van die begin af het die skuif van Stellenbosch na UWK vir my ander uitdagings en heel ander agendas meegebring. Die groter agenda van sosiale transformasie is miskien dieselfde maar dit lyk heel anders in 'n konteks waar die hegemonie van Afrikaner nasionalisme en elitisme deurbreek moet word as by 'n universiteit soos UWK waar 'n "plek van kwaliteit en 'n plek om in te groei" gevestig moet word. Waar ek as student my beywer het vir die transformasie van Stellenbosch (as dorp, die universiteit en die NG gemeentes in Stellenbosch) ten opsigte van sosiale geregtigheid, gaan dit vir my by UWK daaroor om 'n bydrae te lewer om institusionele strukture te help vestig in 'n konteks waar transformasie weliswaar nog op die agenda is, maar dan op die basis wat in die 1970s en 1980s reeds vasgelê is. Ek ondersteun institusionele transformasie ten volle maar hoef nie aan die voorpunt daarvan te staan nie en lewer eerder'n bydrae om die merkwaardige sosiale eksperiment wat die UWK is te maak werk.

In kort, gegewe 'n ander retoriese konteks (teologies eerder as filosofies, van US na UWK, van Stellenbosch na Bellville en weer terug, ekumenies 
eerder as die fokus op die NG Kerk), wil ek graag die kreatiewe spanninge in Geloof sonder sekerhede uitlig en daarmee in gesprek met Anton van Niekerk tree oor waar hy die klem laat val. In 'n ander konteks sou ek bes moontlik die teenoorgestelde wou beklemtoon.

\section{Ortodoksie en ortopraksie}

Van Niekerk maak dit duidelik dat hy 'n gesprek oor leerstellings doelbewus onderbeklemtoon. Hy meen dat "die groeiende geringskatting van die getuienis en die gevolglike ontkragting van die rol van die kerk in die wêreld te make het met 'n serebraal-teoretiese geloofsbeskouing wat selde sigbaar word in 'n praktyk en leefwyse wat 'n wesenlike verskil maak aan die lewe waarin ons ons bevind" (p 44). Hy stel die sterk oortuiging (in kursief gedruk) "dat ortopraksie baie belangriker vir die kerk en die lewe in die geloof is as ortodoksie" (p 35). Geloof is daarom ten beste te verstaan as "lewe in die liefde" (p 128-130). Hy het dit hier teen 'n verstarde gereformeerde ortodoksie maar ook teen fundamentalisme wat altyd maar weer kop uitsteek in evangeliese kringe. Hy noem egter ook die "voortgaande, uiters onverkwiklike impasse in die NG Kerk familie oor die Belydenis van Belhar om mekaar in eenheid te vind" ( $p$ 35). Die voorbeeld is opmerklik omdat die Belydenis van Belhar vanuit die kerklike praktyk van skeiding op grond van ras juis die klem laat val op die regte leer en daarom telkens dwaalleer afwys. Hier is 'n voorbeeld waar ortodoksie as fundamenteel belangrik geag is ter wille van ortopraksie. Die uitklaar van waar die probleem in die kerklike praktyk lê (gegewe die invloed van apartheid), kon alleen op ideologiese en daarom teologiese vlak bereik word. Die afkondiging van 'n status confessionis in 1982 was nie die produk van 'n "onverkwiklike impasse" nie, maar 'n reaksie op 'n situasie waar "oop gesprek" nie meer moontlik was nie en waar 'n belydenis van geloof as die enigste uitweg beskou is (sien Smit 1984).

In ekumeniese kringe is die spanning tussen ortodoksie en ortopraksie veral aan die orde gestel deur 'n projek van die Wêreldraad van Kerke oor "Ecclesiology and Ethics". Dit is gestruktureer in die vorm van drie konferensies oor Costly Unity (Ronde, 1993), Costly Commitment (Tantur, 1994) en Costly Obedience (Johannesburg, 1996). Die projek was 'n poging om interaksie te bevorder tussen diskoers oor "Faith and Order" (oor leer 
en kerkreg) en diskoers oor "Life and Work" oftewel "Church and Society" (oor die sosiale relevansie van die kerk). Dit het gespruit uit aksentverskille oor 'n toepaslike verstaan van wat die kerk moet doen in die samelewing en oor wat die kerk moet doen, oftewel oor ortodoksie en ortopraksie. Die finale verslag dui daarop dat hier'n feitlik onoorbrugbare kloof aanwesig is. Beide kante is daarvan oortuig dat so 'n brug gebou moet word, maar kom nooit werklik bymekaar uit nie (sien Best \& Robra 1997:vii). Dit is uiteraard onhoudbaar maar nietemin tekenend van onderliggende spanninge in die ekumeniese beweging.

Hierdie spanning het sedertdien vernietigende gevolge in die SuidAfrikaanse konteks gehad, al is die projek juis vanuit hierdie konteks aan die orde gestel. Die Suid-Afrikaanse Raad van Kerke het as organisasie in duie gestort, 'n mens sou kon sê (ten minste ten dele) as gevolg van 'n oorbeklemtoning van die sosiale relevansie van die kerk in die samelewing in die stryd teen apartheid sonder om genoegsaam aan die besondere identiteit van die kerk aandag te gee. Die rol van die SARK in 'n veranderende omgewing kon daarom nie betyds herdefinieer word nie. Daar is pogings om die SARK weer op die been te kry, maar dit kan nie alleen plaasvind by wyse van nuwe programme rondom die sosiale relevansie van die kerk nie. Daarenteen is ekumeniese samewerking op plaaslike vlak (by begrafnisse, in skole en in die werkplek) springlewendig terwyl nasionale inisiatiewe nie dieselfde entoesiasme ontlok nie.

In die Departement Godsdiens en Teologie aan die UWK het ons sedert 2012 'n projek rondom "Ecumenical Studies and Social Ethics" waarin hierdie spanning van naderby ondersoek word (sien veral Conradie 2013b). Dit sal kulmineer in 'n konferensie oor "Ecclesiology and Ethics: The State of Ecumenical Theology in Africa" wat beplan word vir Junie 2015. Die interessante is dat hierdie spanning ook in Afrika-teologie aanwesig is, tussen diegene wat enkulturasie of verinheemsing beklemtoon (en daarom kwessies rondom leierskap, leer en liturgie aan die orde stel) en ander wat 'n teologie van bevryding of rekonstruksie artikuleer, of wat fokus op die emansipasie van vroue in die Afrika-konteks. Nog ander probeer om enkulturasie te verstaan in terme van bevryding in die sin dat kulturele en psigologiese bevryding (in die vorm van verinheemsing) pas moontlik is op grond van sosio-ekonomiese bevryding (sien Mugambi 2003:71, 214). Dit is ook opmerklik dat die fokus op plaaslike vlak dikwels op "ecclesiology" val, 
terwyl nasionale en internasionale konferensies tipies eerder op "ethics" fokus (sien Sakupapa 2013).

Die UWK-projek val tans onder die nuwe Desmond Tutu Centre for Spirituality and Society - waarin die spanning tussen ortodoksie en ortopraksie juis lewend gehou word. Dit gaan veral oor die logika van die "en" wat spiritualiteit en samelewing met mekaar verbind. Desmond Tutu is in sy persoon en bediening 'n sprekende voorbeeld van iemand by wie die sosiale rol van die kerk alleen moontlik is vanuit 'n spesifieke spiritualiteit wat gevoed word uit 'n bepaalde visie oor die "verheerliking" van Jesus Christus (sien Tutu 2005:93). Die bron van inspirasie vir sosiale transformasie is daardie transfigurasie. In kort, die klem op ortopraksie is klaarblyklik belangrik, maar ek twyfel of dit vrugbaar is om die profete en die mistici teenoor mekaar te stel. Die regte leer is belangrik ter wille van die regte lewe. Anders gestel: wanneer gesprek oor die regte lewe vasloop, kan dit alleen herlei word na gesprek oor die regte leer. Die beste voorbeeld van die volhou van 'n kreatiewe spanning tussen ortodoksie en ortopraksie is miskien die gesprekke binne gereformeerde kerke oor 'n status confessionis. Hier is die Belydenis van Belhar toonaangewend, maar dit kom ook na vore in debatte oor 'n processus confessionis (sien Möller 1996) rondom ekonomiese ongeregtigheid en ekologiese verwoesting, byvoorbeeld by die Akkra-Verklaring van 2004.

\section{Geloof sonder sekerhede?}

Van Niekerk verduidelik dat die titel van sy boek dui op 'n geloof wat van meet af aangevreet word deur die ervaring van twyfel en onsekerheid. Hy wys op "die radikaliteit van die onsekerheid waarmee ons moet leer klaarkom in ons huidige wêreld en tyd" (p 16). Geloof sonder sekerhede beteken egter nie soseer onsekerheid nie en dui nie alleen op onseker tye nie. Geloof sonder sekerhede dui eerder daarop dat die inhoud van die geloof met 'n onpeilbare misterie te make het ( $\mathrm{p} 21)$. Dit word uiteengesit in 'n voortreflike hoofstuk oor "God as misterie van die wêreld en die taal". Die misterie is kenbaar in die vorm van verwondering, maar nie volledig peilbaar nie. 
Die polemiese konteks waarbinne Van Niekerk skryf oor geloof sonder sekerhede is insgelyks die gewaande sekerhede van 'n fundamentalistiese of evangeliese ortodoksie. Ek vermoed hy verwoord en verdedig hier die standpunt van sy implisiete lesers wat gelowig is "by choice" eerder as "by convention" ( $p$ 33) en wat daarom reeds afskeid van fundamentalisme geneem het maar tog nog (in Stellenbosse koshuise?) daarmee gekonfronteer word. Hy het dit egter ook teen 'n koerslose relativisme, miskien 'n bepaalde vorm van postmodernisme waarbinne van onsekerheid 'n deug gemaak word en waarbinne Heisenberg se onsekerheidsbeginsel 'n ikoniese posisie verkry het. Verder wys hy teen sciëntistiese opvattings daarop dat wetenskap juis deur hipotetiese onsekerheid en die moontlikheid van falsifisering (Karl Popper) gekenmerk word. Hy meen tereg dat 'n mens katvoet moet wees vir wetenskaplikes wat alte seker is van hulle teorieë (p 185). Daarenteen veronderstel geloof wel 'n soort standvastigheid wat uit 'n langtermyn verbintenis (commitment) spruit. Hoewel dit mag lyk na 'n weerspreking van sy eie argument, is daar vanuit hierdie standvastigheid wel ruimte vir geloofsekerheid of ten minste dan geloofsversekerdheid, wat berus op versekering deur 'n ander ( $p$ 189). Hier is dus sprake van ontmoetingskennis eerder as wetenskaplike kennis of forensiese bewyse.

Van Niekerk verwys in die verband (p 189) na die uitstekende boek van James McClendon ('n Baptis en vooraanstaande teoloog) en James Smith ('n self-erkende ateïs) met die titel Convictions (1994, tweede uitgawe). McClendon en Smith toon aan hoedat mense hulle menings (beliefs) en oortuigings (convictions) binne 'n singewende oriëntasieraamwerk orden. Dit word saamgebundel binne 'n konstellasie van simbole wat as 'n stel oortuigings (a "set" or "cluster" of convictions") beskryf word. Hoewel só 'n stel waardes en oortuigings langsamerhand gevorm word en wel kan verander, is dit nietemin stabiel genoeg om aan iemand 'n bepaalde standvastigheid te verleen, soveel so dat dit nie kan verander sonder dat iemand se identiteit daarmee radikaal geherdefinieer word nie. Dit is dan soortgelyk aan 'n godsdienstige bekering, maar kan ook vergelyk word met iemand wat uit die hartjie van die platteland kom en uiteindelik as 'n kosmopolitaanse stadsmens tereg kom.

Ek is dit op al hierdie punte volledig met Van Niekerk eens. Ek lees egter die breër konteks ietwat anders. In 'n pluralistiese en sogenaamde gesekulariseerde Suid-Afrikaanse konteks word die kritiek teen die 
gewaande sekerhede van fundamentalisme as vanselfsprekend aanvaar. Ten spyte van die kulturele invloed wat fundamentalisme steeds in sekere kringe uitoefen, is dit in publieke diskoers volledig gediskrediteer. In SuidAfrika word positivisme eweneens wyd bevraagteken gegewe die aandrang op publieke intellektuele en die kritiek teen universiteite as ivoortorings. Hierdie menings word geïnternaliseer in die dominante selfverstaan van universiteitsdosente by UWK, al is dit lank nie by almal aanwesig nie. Die retoriese konteks is daarom hier belangrik. Myns insiens is dit ten minste net so belangrik om die relativering van godsdienstige oortuigings aan te spreek.

Die moeiliker vrae hang saam met die publieke rolvan godsdiens. Die reg op godsdienstige affiliasie word grondwetlik verskans en daar is wye erkenning vir die rol van godsdienstige groepe om sosiale kohesie te verseker. Veral kerke word heimlik bewonder vir hulle vermoë om aanhangers te trek en invloed uit te oefen deur morele leierskap - 'n invloed waarvan kerkleiers vermoedelik self minder seker is. Die dominante persepsie is egter eerder dat enige aksent op godsdienstige identiteit gevaarlik is en hoogstens geduld moet word, dat toleransie en respek vir ander se godsdienstige identiteit die wagwoord behoort te wees en dat dit sal baat om eerder te fokus op wat mense in gemeen het as op godsdienstige verskille. Laasgenoemde (en veral teologiese debatte oor ortodoksie) moet liefs onderspeel word in nasionale belang of ten minste ter wille van ekumeniese welwillendheid.

Die vraag wat dan opkom, is of godsdiens nie eintlik triviaal is nie - sodat die een godsdienstige identiteit goedskiks vir 'n ander verruil kan word. In 'n mooi boek met die titel In Praise of Doubt ('n sinspeling op Erasmus se "Tot lof van die sotheid" waarvan Van Niekerk ook veel maak, sien p 91114), wys Peter Berger en Anton Zijderveld op die verskil tussen die mate van sekerheid wat met morele oordele en met godsdienstige oortuigings gepaard gaan. Hulle sê: "We can live with considerable uncertainty concerning our cognitive definitions of reality while at the same time being able to make moral judgements with great certainty" (Berger en Zijderveld 2009:121). Dit, só lyk dit vir my, is inderdaad ook in SuidAfrika die geval. Mense kan godsdienstig glo min of meer net wat hulle wil, solank as wat hulle dit net vir hulleself hou. Godsdiens kan daarom getolereer word omdat dit triviaal is. Daarenteen word morele oordele met veel meer stelligheid gemaak ( $\mathrm{al}$ is dit altyd meer ingewikkeld wanneer dit 
by etiese analise kom). Twee voorbeelde: Mense is tereg bereid om hulle bure aan te kla vir erge lyfstraf op kinders wat in die privaatheid van hulle eie huise toegedien word. Dieselfde geld nog meer van kinderpornografie of pedofilie. Rassistiese grappe wat rondom 'n braaivleisvuur vertel word en deur sosiale media versprei word, kan maklik 'n nasionale debat ontlok. Hierteenoor is kettery in die verlede op die brandstapel veroordeel, selfs in Calvyn se tyd in Genève. Dit was destyds allesbehalwe triviaal, maar nou is sulke straf vir kettery ondenkbaar. Ek kan byvoeg dat egbreuk en sedelike losbandigheid insgelyks destyds krimineel vervolg is, terwyl dit vandag weliswaar nie triviaal is nie maar wel as 'n private aangeleentheid beskou word.

Die subtitel van Berger en Zijderveld se boek, "How to have Convictions without Becoming a Fanatic" dui daarop dat hulle (soos Van Niekerk) soek na 'n singewende en rigtinggewende geloof, sonder sekerhede, ten einde te kan deurstuur tussen fundamentalisme en relativisme. Die vraag is nietemin wat die belang is van wat Berger elders "ultimate reality" noem. Gegewe die onderskeid wat Dietrich Bonhoeffer in sy boek Ethics (2005) maak tussen dit wat "ultimate" en wat "penultimate" is, wil dit lyk asof die sosiale konstruksie van gemeenskaplike waardes veel belangriker is as die sosiale konstruksie van die werklikheid - oftewel die rol van 'n simboliese universum waarmee Berger in sy vroeëre werk die rol van godsdiens verbind het (sien Berger 1967; Berger \& Luckmann 1967). Watter rol speel geloof as 'n oriëntasie raamwerk dan wel? Ek meen dat die antwoord op hierdie vraag saamhang met die rol van misterie. Dit wat "ultimate" is, is tegelyk ook minder evident, meer van 'n misterie. Daarom kan meer klaarheid verkry word in terme van morele oordele as ten opsigte van die sosiale konstruksie van die "laaste werklikheid". Hoe meer kompleks en omvattend 'n kategorie is, hoe minder klaarheid en hoe meer onsekerheid is daarmee saam onvermydelik. Die vraag bly dan nietemin wat die morele belang van 'n visie op die laaste werklikheid uiteindelik is. Dit is die klassieke teologiese vraag na die verhouding tussen die indikatief van genade en die imperatief van 'n lewe vanuit daardie genade, oftewel na die verhouding tussen dogmatiek en etiek, tussen ortodoksie en ortopraksie. Die paradoks is hier dat dit wat van voorlaaste belang is, oënskynlik meer belangrik is as dit wat as van die allerlaaste belang geag word. Of teologiese nadenke sigself gerieflik daarby kan berus, is 'n ander vraag. 


\section{Geloofskennis en wetenskaplike kennis}

Van Niekerk het as godsdiensfilosoof meermale bydraes gelewer oor die verhouding tussen geloof en wetenskap, of eerder, tussen geloofskennis en wetenskaplike kennis (sien alreeds Van Niekerk 1982, 1983). Hy is diep onder die indruk van die uitdagings wat die moderne natuurwetenskap aan die geloof stel, veral in terme van 'n gangbare wêreldbeeld (p 163v). Hy argumenteer dat die wetenskappe nie 'n monopolie op betroubare kennis het nie ( $\mathrm{p}$ 179). Die waarheid het meerdere dimensies wat nie gereduseer kan word tot wetenskaplike eksaktheid of forensiese bewysgewing nie. Hiermee verwerp hy die reduksionisme van die godsdienskritiek van Richard Dawkins en ander ( $p$ 170). Hy het tereg ook nie veel ooghare vir teorieë oor intelligente ontwerp nie (p 175) en beklemtoon dat die Bybel geen handboek vir enige wetenskap is nie ( $p 57,180)$. Hy meen dat geloof wat verhef word tot wetenskap tot bygeloof lei (p 191). Andersom, verword wetenskap wat buite die terrein van die wetenskap self beweeg in ideologie ( $p$ 192). Hy beklemtoon daarom dat "Wetenskap en geloof bedien sigself van logies verskillende soorte kennisuitsprake, wat onderskeidelik verskillende soorte waarhede uitdruk" (p 190) en wat daarom "op totaal verskillende maniere verantwoord word" ( $p$ 183). Hy voeg by dat "Wetenskap en godsdiens praat selde oor dieselfde soort werklikheid, en praat selde op 'n vergelykbare manier oor die wêreld" (p 190). Kortom, "Dit beteken alleen dat wetenskap en godsdiens met fundamenteel andersoortige vrae werk" ( $\mathrm{p}$ 183 , kursief in die oorspronklike).

Van Niekerk se standpunt berus op Wittgenstein se voorstel dat verskillende taalspele erken kan word wat nie tot mekaar herlei kan word nie. Hy verwys nie na Stephen Jay Gould se opvatting dat godsdiens en wetenskap as "nonoverlapping magisteria" beskou kan word nie (elk met 'n eie domein van gesag), maar wel na Tertullianus se vraag "Wat het Athene met Jerusalem te make?” (p 166 stel die vraag wel andersom). Van Niekerk bepleit geensins 'n terugkeer na Tertullianus (en die voorrang wat aan geloofskennis gegee word nie), maar beklemtoon wel die verskil tussen geloofskennis en wetenskaplike kennis en die gevaar daarvan om hulle te laat versmelt. Die argument is myns insiens helder en oortuigend.

In eietydse diskoers oor godsdiens en wetenskap word nietemin tipies die teenoorgestelde gevaar beklemtoon, naamlik dat geloof en wetenskap 
van mekaar geskei word. Daar bestaan talle tipologieë oor die verhouding tussen godsdiens en wetenskap Die meeste bydraes verwys terug na Ian Barbour (1997:77-105) se voorstel dat onderskei kan word tussen modelle wat berus op "konflik", “onafhanklikheid", "dialoog” en "integrasie”. Die retoriek is klaarblyklik gemik op die gevare van skeiding sodat ten minste "dialoog", "konvergensie" of "konsonansie" (Peters 1998) bepleit word ten einde die grense van sowel wetenskap as godsdiens aan te dui maar om ook vrugbare interaksie aan te moedig (sien Peters \& Hewlett 2003).

Ek gee toe dat die vermenging van wetenskap en geloof katastrofale gevolge inhou. Die gevare van boedelskeiding is egter self nog groter. Myns insiens is dit nuttig om aan één multidimensionele werklikheid te dink. Op die voetspoor van George Ellis en Nancey Murphy (1996) meen ek dat 'n mens kan praat van verskillende vlakke van kompleksiteit waaraan 'n bepaalde hiërargie van die wetenskappe korrespondeer (met al die gevare van só 'n hiërargie inaggenome). Die gevaar van reduksionisme is dan een waar twee vlakke van kompleksiteit met mekaar verwar en vervloei word sodat die een tot die ander gereduseer word. Die gevaar van skeiding (oftewel diskonneksie) is die teenoorgestelde, naamlik dat 'n hoër vlak van kompleksiteit beskou word as onverwant tot enige laer vlak. Dit is belangrik om raak te sien dat wetmatighede wat op laer vlakke van kompleksiteit geld ook van toepassing is op hoër vlakke van kompleksiteit. Sulke wette bepaal wat as moontlik geag word, behalwe dat die wette self veel meer kompleks is as wat reduksionisties erken word. Dit beteken byvoorbeeld dat die geloofwaardigheid van geloofsuitsprake wat kennis vanuit ander dissiplines reëlreg weerspreek (oor die oerknal of oor evolusie) aangetas word (sien ook p 24-29, 168-169). Die nuwe moontlikhede wat ontstaan op hoër vlakke van kompleksiteit (die rol van bewussyn, taal simbole) kan egter nie volledig herlei word na laer vlakke van kompleksiteit nie.

Die gevaar van diskonneksie bestaan op verskeie vlakke. In die menswetenskappe is die gevaar om menswees te verstaan vanuit twee onderskeie biofisiese en sosio-kulturele perspektiewe wat bymekaar gehou moet word deur 'n dun lagie psigologiese sement (wat lei tot debatte oor die verhouding tussen "nurture" en "nature"). Insgelyks kan ekonomiese teorieë wat voorgesette ekonomiese groei veronderstel op die rotse loop wanneer die ekologiese veranderlikes wat op 'n biofisiese vlak geld nie in ag geneem word nie. 
Die gevaar van skeiding is vir Christelike teologie van deurslaggewende belang, veral gegewe langdurige dualistiese tendense. Die krag van dualisme lê daarin dat die gevaar van reduksionisme raakgesien word. Aangesien integrasie onmoontlik is, word twee vlakke van kompleksiteit gehandhaaf sodat teenpole al twee beklemtoon word. Een sprekende voorbeeld is die klem in Pentekostalisme op die werking van die "Gees" - wat tot uitdrukking kom in heel liggaamlike vorms van aanbidding, in die aandrang op liggaamlike genesing en die omarming van audiovisuele tegnologie. Die probleem bly egter dat die teenpole nie met mekaar in verband gebring word nie. In ekologiese teologie is die vraag nie bloot na 'n toereikende omgewingsetiek of skeppingsteologie nie, maar na hoe teologiese en ekologiese diskoers met mekaar verband hou. Dit laat ruimte vir 'n ekologiese kritiek van die Christelike tradisie en vir 'n Christelike kritiek teen ekologiese verwoesting (sien Conradie et al 2014).

Die gevaar is dat teologiese taal geskei kan word van die onderliggende breinfunksies, van liggaamlike instinkte en van die materiële werklikheid opsigself. Dit laat die vraag hoe die Woord wat vlees geword het saamhang met die vleis en bloed waarin dit gestalte gevind het. Is die Woord afkomstig van die goddelike Vader veronderstel om 'n geordende logika in te dra in 'n vervroulikte chaos? Insgelyks, wat beteken die inwoning van die Gees binne 'n bepaalde omgewing? Hoe moet die transformasie deur die Gees dan verstaan word? Sekerlik nie as 'n kwasi-materiële spookagtige krag aanwesig in die wêreld nie! Wanneer skeiding die botoon voer, lei dit daartoe dat geloofstaal idealisties word in die sin dat dit die blote uitdrukking van idees word wat kwalik die sosiale en liggaamlike kontekste waarin dit tot uitdrukking kom, kan verander. In teologiese terme is hierdie die gevaar van dosetisme wat op talle vlakke kop uitsteek, insluitende in die hermeneutiek.

\section{Slotsom}

Dit is myns insien daarom van groot belang om te beklemtoon dat die natuurwetenskappe, die sosiale wetenskappe, filosofie, die kunste en teologie almal betrekking het op een en dieselfde meervlakkige werklikheid. Al hierdie dissiplines is betrokke in 'n gemeenskaplike taak om sin te maak van die wêreld rondom ons. Brian O' Connell (die 
vorige UWK-rektor) praat gereeld en tereg van die taak van universiteite as een van "sense-making". Enige finale skeiding van die dissiplines loop die gevaar dat die filosofiese (en metafisiese) veronderstellings van al die wetenskaplike dissiplines onderskat word, dat die onderliggende waardes van wetenskaplike ondersoek geïgnoreer word en dat enige só 'n dissipline alte maklik irrelevant word. Dit geld veral van die Christelike teologie. Die geloofwaardigheid van teologiese uitsprake oor God is afhanklik van 'n verduideliking oor hoe God met die werklikheid verband hou (sien alreeds Bavinck 2004:474). Dit het betrekking op ons kennis van God as alle uitsprake oor transendensie van benede kom (Harry Kuitert), maar dit geld ook van die geloofwaardigheid van die evangelie dat God die wêreld liefhet, so lief gehad het dat God die wêreld as woonplek gekies het en bereid was om daarvoor te sterf. Anders gestel: die prys wat betaal word wanneer geloofskennis nie meer met wetenskaplike en ander vorms van kennis in verband gebring kan word nie is doodgewoon irrelevansie. Dit beteken nie dat teologie en wetenskap toegelaat moet word om te vervloei of dat integrasie moontlik is nie. Dit beteken wel dat teologie en wetenskap dit oor een en dieselfde werklikheid het.

Dit vra daarom 'n meer moeisame en morsige gesprek tussen teologie en ander dissiplines ten einde gemeenskaplike onderliggende probleme te identifiseer en aan te spreek. Ek gee toe dat so 'n gesprek alleen moontlik is indien die een nie tot die ander gereduseer word nie en dat die eie partikulariteit van elke dissipline erken moet word. Dit is egter slegs moontlik wanneer raakgesien word dat die onderskeidings tussen dissiplines wat histories ontstaan het altyd voorlopig en in 'n sin kunsmatig is.

'n Herkenning van onreduseerbare kompleksiteit bring mee dat geen een dissipline genoegsaam is om daardie kompleksiteit te verreken nie. Dit beteken dat geloofskennis nie genoegsaam is of in isolasie van wetenskaplike kennis kan bestaan nie. Net is ortopraksie sonder ortodoksie nie moontlik nie. 'n Mens moet immers weet wat die regte ding is om te doen voordat jy van ortopraksie kan praat. Die spanning tussen sekerheid en voorlopigheid lê op 'n ietwat ander vlak, maar ook daar benodig 'n erkenning van die voorlopigheid van geloofsuitsprake die herkenning van 'n vastrapplek ten einde die volgende tree te kan gee. 


\section{Verwysings}

Barbour, Ian G 1997. Religion and Science: Historical and Contemporary Issues. San Francisco: Harper.

Bavinck, Herman 2004. Reformed Dogmatics, Volume 2: God and Creation. Grand Rapids: Baker Academic.

Berger, Peter L 1967. The Sacred Canopy: Elements of a Sociological Theory of Religion. New York: Doubleday.

Berger, Peter L \& Luckmann, Thomas 1967. The Social Construction of Reality: A Treatise in the Sociology of Knowledge. New York: Penguin Press.

Berger, Peter L \& Zijderveld, Anton 2009. In Praise of Doubt: How to have Convictions without Becoming a Fanatic. New York: HarperCollins.

Best, Thomas F \& Robra, Martin (eds.) 1997. Ecclesiology and Ethics: Ecumenical Ethical Engagement, Moral Formation and the Nature of the Church. Geneva: World Council of Churches.

Bonhoeffer, Dietrich 2005. Ethics, Dietrich Bonhoeffer Works 5, Minneapolis: Fortress Press.

Bosch, David J 1991. Transforming Mission: Paradigm Shifts in Theology of Mission. Maryknoll: Orbis Books.

Conradie, Ernst M 2006. Lewe Anderkant die Dood? In Gesprek oor die Hoop op die Opstanding uit die Dood. Wellington: Lux Verbi BM.

Conradie, Ernst M 2013a. "A Semiotic Notion of Transcendence”. Studia Historiae Ecclesiasticae, Vol. 39 (Supplement), 39-54.

Conradie, Ernst M (ed.) 2013b. Notions and Forms of Ecumenicity: South African Perspectives. Stellenbosch: Sun Press.

Conradie, Ernst M 2013c. Saving the Earth? The Legacy of Reformed Views on "Re-creation". Studies in Religion and the Environment 8. Berlin: LIT Verlag.

Conradie, Ernst M, Bergmann, Sigurd, Deane-Drummond Celia \& Edwards, Denis (eds) 2014. Christian Faith and the Earth: Current Paths and Emerging Horizons in Ecotheology. London: T\&T Clark. 
Ellis, George FR \& Murphy, Nancey 1996. On the Moral Nature of the Universe. Minneapolis: Fortress Press.

McClendon, James W \& Smith, James M 1994. Convictions: Defusing Religious Relativism (revised edition). Eugene: Wipf \& Stock.

Möller, Ulrich 1996. Status confessionis? Confessing our faith in the context of economic justice. Reformed World 46, 138-144.

Mugambi, Jesse, NK 2003. Christian Theology and Social Reconstruction. Nairobi: Acton Publishers.

Peters, Ted F (ed) 1989. Cosmos as Creation: Theology and Science in Consonance. Nashville: Abingdon Press.

Peters, Ted F \& Hewlett, Martin 2003. Evolution from Creation to New Creation: Conflict, Conversation and Convergence. Nashville: Abingdon Press.

Sakupapa, Teddy C 2013. "Local Ecumenism in the Zambian Context". In: Ernst M Conradie (ed.): Notions and Forms of Ecumenicity: South African Perspectives. Stellenbosch: Sun Press, 156-166.

Smit, Dirk J 1984. “Wat Beteken Status Confessionis?”. In: G Daan Cloete \& Dirk J Smit (reds): 'n Oomblik van waarheid. Kaapstad: Tafelberg, 16-40.

Tutu, Desmond M 2005. God has a Dream: A Vision of Hope for our Time. New York: Double Day.

Van Niekerk, Anton A 1982. "Rasionaliteit, wetenskap en geloof". Nederduitse Gereformeerde Teologiese Tydskrif 23, 150v.

Van Niekerk, Anton A 1983. "Die grense van die kritiese rede”. Tydskrif vir Geesteswetenskappe 23, 7-27.

Van Niekerk, Anton A 1992. Rasionaliteit en Relativisme: Op soek na 'n rasionaliteitsmodel vir die menswetenskappe. Pretoria: RGN.

Van Niekerk, Anton, A 2014. Geloof sonder Sekerhede: Hoe kan ek nog glo? Kaapstad: Lux Verbi. 